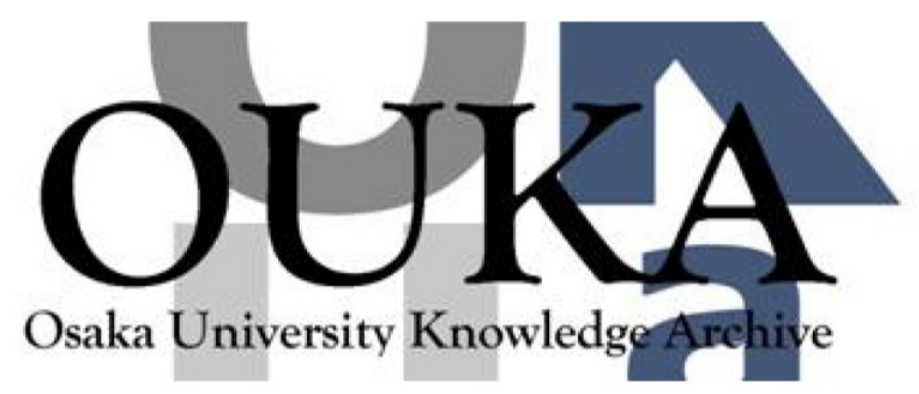

\begin{tabular}{|c|l|}
\hline Title & $\begin{array}{l}\text { Thermodynamics of Equi Librium Distribution of } \\
\text { Solute Elements in Solidification Process of } \\
\text { Steel }\end{array}$ \\
\hline Author(s) & Morita, Zen-ichiro; Tanaka, Toshihiro \\
\hline Citation & $\begin{array}{l}\text { High Temperature Materials and Processes. 22(5- } \\
\text { 6) } 329-p .335\end{array}$ \\
\hline Issue Date & 2003 \\
\hline oaire:version & VoR \\
\hline URL & https://hdl.handle. net/11094/26033 \\
\hline rights & \\
\hline Note & \\
\hline
\end{tabular}

Osaka University Knowledge Archive : OUKA

https://ir. Library. osaka-u. ac. jp/

Osaka University 


\title{
Thermodynamics of Equilibrium Distribution of Solute Elements in Solidification Process of Steel
}

\author{
Zen-ichiro Morita ${ }^{1}$ and Toshihiro Tanaka ${ }^{2}$ \\ ${ }^{1}$ Emeritus Professor, Osaka University, Osaka, Japan \\ ${ }^{2}$ Department of Materials Science \& Processing, Osaka University, Osaka, Japan
}

\begin{abstract}
Thermodynamics of the equilibrium distribution of solute elements between solid and liquid phases in iron alloys was discussed in this work. New parameters have been introduced to present the effects of soluteinteractions on the equilibrium distribution in multicomponent alloys. Some applications of those new parameters were shown to explain solid/liquid distribution of solutes in solidification of steels.
\end{abstract}

\section{INTRODUCTION}

Information on the equilibrium distribution coefficients $k_{0}^{X}$, the ratio of the equilibrium concentration of a solute $X$ in solid phase to that in liquid phase, of solute elements between solid and liquid phases is indispensable for the analysis of microsegregation of the elements during solidification of steels. The values of $k_{0}^{X}$ of solute elements in multicomponent iron alloys seem to be different from those obtained from their binary phase diagrams because of solute-interactions. The influence of the soluteinteractions on $k_{0}^{X}$, however, has not been elucidated thoroughly so far. Thus, the authors have studied the equilibrium distribution of various solute elements in iron base multi-component alloys /1-4/. The purpose of this work is to present thermodynamics of $k_{0}^{X}$ in iron base multi-component alloys, and then to discuss the effect of the solute-interactions on the equilibrium distribution of some elements in $\mathrm{Fe}$ alloys.

\section{THERMODYNAMICS OF EQUILIBRIUM DISTRIBUTION OF SOLUTES BETWEEN SOLID AND LIQUID PHASES}

The equilibrium distribution coefficient $k_{0}^{X}$ is given thermodynamically in the following Eq. 1/1-3/:

$$
\begin{aligned}
\ln k_{0}^{X} & =\ln \frac{N_{X}^{S}}{N_{X}^{l}} \\
& =\frac{\left(\mu_{X}^{0, l_{i}}-\mu_{X}^{0, S}\right)}{R T}+\ln \gamma_{X^{\prime}}^{l}-\ln \gamma_{X}^{S}
\end{aligned}
$$

where $\mu_{X}^{0 . l}-\mu_{X}^{0.5}:$ the free energy of fusion of pure element $X, \gamma_{X}$ : activity coefficient of solute $X, R$ : gas constant, $T$ : absolute temperature. Superscripts $L$ and $S$ show liquid and solid phases, respectively.

The activity coefficient $\gamma_{X}$ in Eq. 1 can be written in terms of Wagner's interaction parameters as follows:

$$
\begin{aligned}
& \ln \gamma_{X} \\
& =\ln \gamma_{X}^{0}+\varepsilon_{X}^{X} N_{X}+\varepsilon_{X}^{\gamma} N_{Y}+\varepsilon_{X}^{Z} N_{z}+\cdots
\end{aligned}
$$

where $N_{\mathrm{X}}$ : mole fraction of solute $X, \gamma_{X}^{0}$ : activity coefficient of solute $X$ in infinite dilution. $\varepsilon_{X}^{Y}, \varepsilon_{X}^{Z} \ldots$ : interaction parameter of $Y, Z, \ldots$ on $X$.

When $\ln \gamma_{X}$ in Eq. 2 for both solid and liquid phases is substituted into Eq. 1, the equilibrium distribution coefficient of solute element $X$ in multi-component iron alloy, $k_{0}^{X, M}$ ( $M$ : Multi-component), can be represented by: 


$$
\begin{aligned}
& \ln k_{0}^{X, M}=\frac{\left(\mu_{X}^{0, L}-\mu_{X}^{0, S}\right)}{R T}+\ln \frac{\gamma_{X}^{0, L}}{\gamma_{X}^{0, S}} \\
& +\left(\varepsilon_{X}^{X, L}-\varepsilon_{X}^{X, S} k_{0}^{X, M}\right) N_{X}^{L} \\
& +\left(\varepsilon_{X}^{Y, L}-\varepsilon_{X}^{Y, S} k_{0}^{Y, M}\right) N_{Y}^{L} \\
& +\left(\varepsilon_{X}^{Z, L}-\varepsilon_{X}^{Z, S} k_{0}^{Z, M}\right) N_{Z}^{l}+\cdots
\end{aligned}
$$

The equilibrium distribution coefficient of solute $X$ in binary iron alloy, $k_{0}^{X .2}$, is given by the following Eq. 4 since $N_{y}^{\prime}, N_{z}^{\prime}$, etc. in Eq. 3 are equal to zero for binary iron alloys.

$$
\begin{aligned}
& \ln k_{0}^{X .2}=\frac{\left(\mu_{X}^{0 . I}-\mu_{X}^{0 . S}\right)}{R T}+\ln \frac{\gamma_{X}^{0 . t}}{\gamma_{X}^{0 . S}} \\
& +\left(\varepsilon_{X}^{X, L}-\varepsilon_{X}^{X, S} k_{0}^{X .2}\right) N_{X}^{\prime}
\end{aligned}
$$

As the third term of Eqs. 3 and 4 has a small contribution to $k_{0}^{X}$ in both binary and multi-component iron alloys /1/ when the concentration of $X$ is dilute, the right-hand side of Eq. 4 is nearly equal to the first to the third terms on the right-hand side of Eq. 3. In addition, the effect of $\mathrm{X}$ on $k_{0}^{Y, M}, k_{0}^{Z, M}$ etc. in $\mathrm{Fe}-\mathrm{X}-\mathrm{Y}-\mathrm{Z} \ldots$ systems can be neglected and they can be replaced by $k_{0}^{X .(M-1)}, k_{0}^{X .(M-1)}$, respectively when the concentration of $\mathrm{X}$ is dilute. Then, Eq. 5 is obtained.

$$
\begin{aligned}
& \ln \frac{k_{0}^{X, M}}{k_{0}^{X, 2}} \\
& =\left\{\varepsilon_{Y}^{Y, I}-\varepsilon_{X}^{Y, .} k_{0}^{Y,(M-1)}\right\} N_{Y}^{l} \\
& +\left\{\varepsilon_{X}^{Z, I}-\varepsilon_{X}^{Z, S} k_{0}^{Z,(M-1)}\right\} N_{Z}^{\prime}+\cdots \\
& =\left\{1-m k_{0}^{Y,(M-1)}\right\} \varepsilon_{X}^{Y, l} N_{Y}^{\prime} \\
& +\left\{1-m k_{0}^{Z,(M-1)}\right\} \varepsilon_{X}^{Z, l} N_{Z}^{l}+\cdots \\
& =\Sigma\left\{1-m k_{0}^{Y,(M-1)}\right\} \varepsilon_{X}^{Y, l} N_{Y}^{l}
\end{aligned}
$$

where $\mathrm{m}=\varepsilon_{X}^{\gamma, s} / \varepsilon_{X}^{Y, J}, \mathrm{~m}^{\prime}=\varepsilon_{X}^{Z . s} / \varepsilon_{X}^{Z . l .}, \ldots \ldots$

The ratio $k_{0}^{X, H} / k_{0}^{X, 2}$ in Eq. 5 indicates the change in $k_{0}^{X, M}$ from $k_{0}^{X, 2}$ due to the effect of soluteinteraction on $k_{0}^{X, M}$ in multi-component iron alloys. Therefore, the authors have defined this ratio as Distribution Interaction Coefficient (DIC) $/ 2 /$. For example, in $\mathrm{Fe}-\mathrm{C}-\mathrm{X}$ ternary alloys, the change in the equilibrium distribution coefficient of solute element $X$ with the concentration of carbon is given as follows.

$$
\ln \frac{k_{0}^{X, 3}}{k_{0}^{X^{\prime, 2}}}=\left(1-m k_{0}^{(\cdot, 2}\right) \varepsilon_{X}^{c, l} N_{c}^{l}
$$

Fig. 1 shows the change in $k_{0}^{X, 3} / k_{0}^{X, 2}$ of various elements in equilibrium of liquid and $\gamma$ phase with the concentration of carbon $N_{r}^{l}$ : in $\mathrm{Fe}-\mathrm{C}$ - $X$ ternary alloys. In this figure, the values of $k_{0}^{X, 3} / k_{0}^{X, 2}$ were obtained by dividing the experimental results /1,4-9/ of $k_{0}^{X, 3}$ for $\mathrm{Fe}$ $C-X$ ternary alloys by the values of $k_{0}^{X, 2}$ listed in Table $1 / 10,11 \%$. The dotted lines in Fig.1 indicate the calculated results from Eq. 6 in case of $m=1$. The reason why the value of $m$ is equal to unity was discussed in detail in the previous work $/ 2 /$.

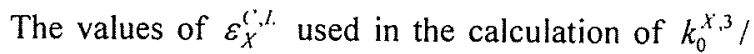
$k_{0}^{X, 2}$ are shown in Table 1.

The values of $k_{0}^{c, 2}$ for carbon in Eq. 6 are known to be nearly $0.3 / 10,11 /$. Therefore, the elements with positive interaction to carbon, i.e., $\varepsilon_{Y}^{\text {(.l. }}>0$, (e.g. $S n$, $S i$,

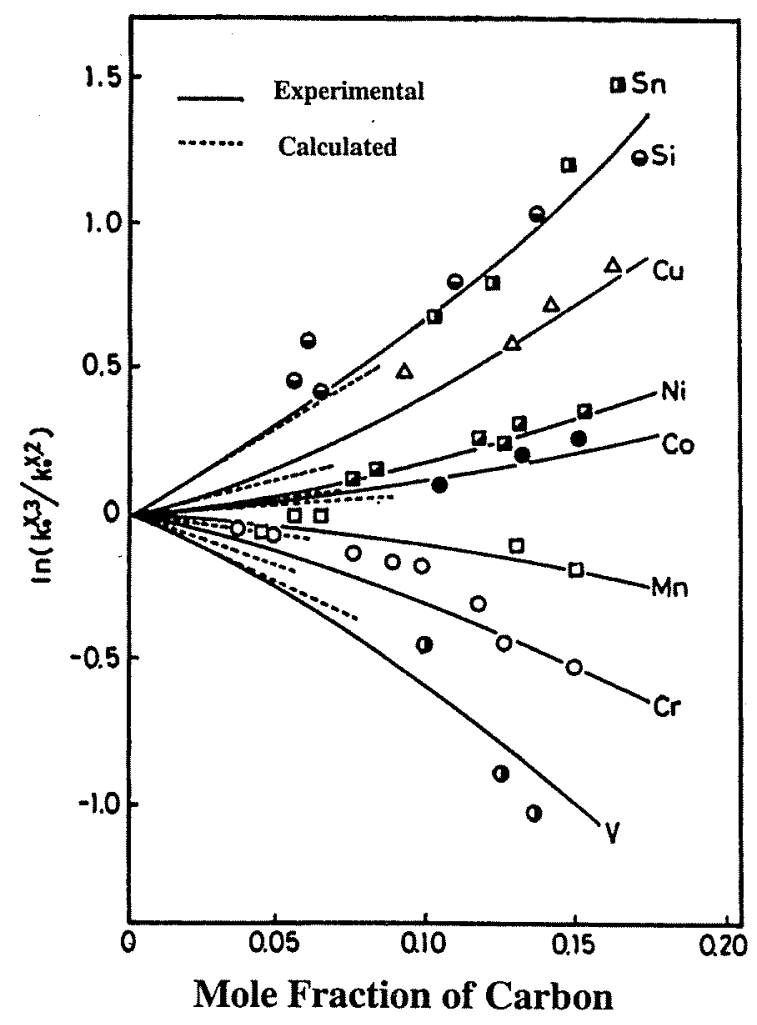

Fig. 1 Change in $\ln \left(k_{0}^{x, 3} / k_{0}^{x, 2}\right)$ of various elements with the concentration of carbon in $\mathrm{Fe}-\mathrm{C}$ base alloys 
Table 1

$k_{0}^{X .2}$ in iron base binary alloys and $\varepsilon_{X}^{(, .,}$in liquid iron alloys.

\begin{tabular}{|c|c|c|c|c|}
\hline & \multicolumn{2}{|c|}{$k_{0}^{X, 2}$} & Ref. & $\begin{array}{c}\varepsilon_{X}^{C, L} \\
\text { (Ref./12/) }\end{array}$ \\
\hline $\mathrm{Co}$ & 0.94 & 0.95 & $/ 10 /$ & 0.99 \\
\hline $\mathrm{Cr}$ & 0.95 & 0.85 & $/ 10 /$ & -5.63 \\
\hline $\mathrm{Cu}$ & 0.90 & 0.70 & $/ 10 /$ & 3.26 \\
\hline $\mathrm{Mn}$ & 0.77 & 0.79 & $/ 11 /$ & -2.67 \\
\hline $\mathrm{Ni}$ & 0.83 & 0.95 & $/ 10 /$ & 1.58 \\
\hline $\mathrm{Si}$ & 0.83 & 0.50 & $/ 10 /$ & 8.90 \\
\hline $\mathrm{Sn}$ & 0.35 & 0.19 & $/ 10 /$ & 8.90 \\
\hline $\mathrm{V}$ & 0.93 & 0.63 & $/ 11 /$ & -6.92 \\
\hline
\end{tabular}

$\mathrm{Cu}, \mathrm{Ni}, \mathrm{Co}$ ) show the positive values of the right handside of Eq. 6, and this implies that $k_{0}^{X}$ increases with increasing the carbon concentration. The reverse is true for the elements having negative interaction to carbon, i.e., $\varepsilon_{x}^{r l}<0$, (e.g. $V, C r, M n$ ). The relationship in Fig. 1 between $\ln \left(k_{0}^{X, 3} / k_{0}^{X .2}\right)$ and the carbon concentration corresponds to the effect of carbon on $k_{0}^{X}$ of various elements in the $\mathrm{Fe}-\mathrm{C}-\mathrm{X}$ ternary alloys as described above.

Consequently, on the basis of Eq. 6 or generally Eq. 5 , we can predict the effect of solute-interactions on the equilibrium distribution of solute elements between solid and liquid phases in multi-component iron alloys. In particular, each term on the right-hand side of Eq. 5 has the form of $\left\{1-m k_{0}^{Y,(M-1)}\right\} \varepsilon_{X}^{Y, I .}$ and the sign and the absolute value of this term determine the effect of the

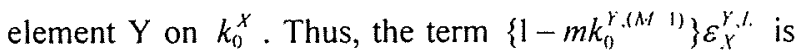
considered as the important parameter for the evaluation of the effect of solute-interactions on $k_{i}^{X}$ in multicomponent alloys. Then, the authors have defined the term $\left\{I-m k_{0}^{Y,(M-1)}\right\} \varepsilon_{X}^{Y . l}$ as Distribution Interaction Parameter $(D I P) / 3 /$ :

$$
\delta_{X}^{Y}=\left\{1-m k_{0}^{Y,(M-1)}\right\} \varepsilon_{X}^{Y, L}
$$

Eq. 5 can be rewritten by the use of $[$ mass $\%]$ as follows.

$$
\log \frac{k_{0}^{X, M}}{k_{0}^{X, 2}}=\Sigma\left\{1-m k_{0}^{Y,(M-1)}\right\} e_{X}^{Y, L}[\operatorname{mass} \% Y]^{l}
$$

where $e_{X}^{Y, t}:$ interaction parameter of $Y$ on $X$.

\section{APPLICATION OF DISTRIBUTION INTERACTION PARAMETER}

\subsection{Fe-Cr-Ni Alloys}

In this section, the effects of solute-interactions on $k_{0}^{X}$ of solute elements in $\mathrm{Fe}-\mathrm{Cr}-\mathrm{Ni}$ base steels were discussed by applying DIC and DIP. Fig. 2 shows our experimental results $/ 3 /$ of the equilibrium distribution coefficient of $\mathrm{Si}, \mathrm{k}_{0}^{\mathrm{si}}$, in $\mathrm{Fe}$-Cr-Ni base steels together with the values reported in Ref./13/. As shown in Fig. 2, the dependence of $k_{0}^{\mathrm{si}}$ on the concentrations of $\mathrm{Ni}$ and $\mathrm{Cr}$ is very small. These results in Fig. 2 can be explained by means of $D I C$ and $D I P$ as described below.

Eq. 8 is rewritten as follows:

$$
\begin{aligned}
& \log \frac{k_{0}^{s, 4}}{k_{0}^{s i, 2}}=\left(1-m k_{0}^{(\dot{r}, 3)}\right) e_{S i}^{(r, l}[\operatorname{mass} \% C r]^{\prime} \\
& +\left(1-m k_{\mathrm{f}}^{N i .3}\right) e_{\mathrm{si}}^{N i . / .}[\operatorname{mass} \% \mathrm{Ni}]^{l}
\end{aligned}
$$

In this work, the values of $k_{0}^{(r .3}$ and $k_{0}^{N t, 3}$ in the $F e$ - 


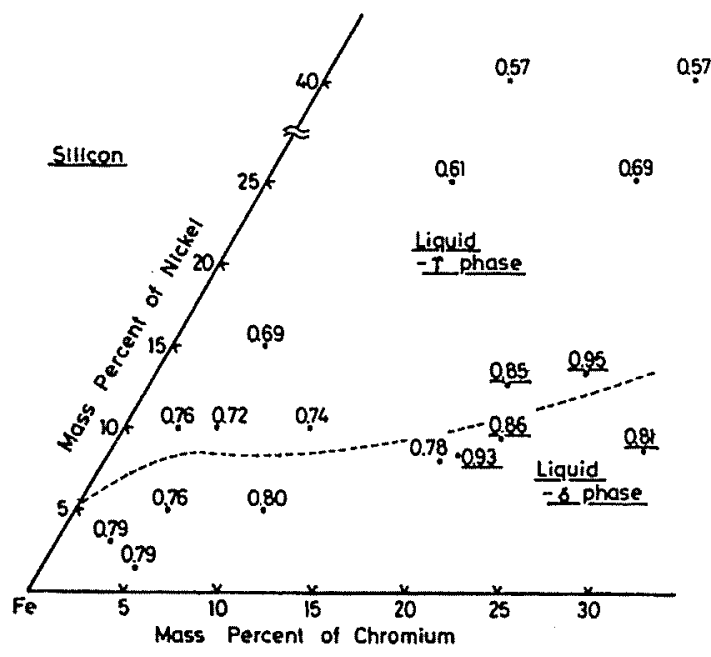

Fig. 2 Equilibrium distribution coefficient of $\mathrm{Si}$ in $\mathrm{Fe}-$ $\mathrm{Cr}-\mathrm{Ni}$ base alloys. Values with underline: Ref./13/

$\mathrm{Cr}-\mathrm{Ni}$ ternary alloys were calculated from the data given by Yamada et al./14/.

Fig. 3 shows the calculated results of the dependence of $k_{0}^{S i .4} / k_{0}^{S i .2}$ on the concentrations of $\mathrm{Ni}$ and $C r$ when $m=r=1$ is assumed. In comparison with $k_{0}^{S i, 4} / k_{0}^{S i, 2}$ in $\mathrm{Fe}-\mathrm{Cr}-\mathrm{Ni}$ base alloys, those in $\mathrm{Fe}-\mathrm{Cr}-\mathrm{C}$ base alloys are shown in Fig. 4. The calculated results for $k_{0}^{s i, 4} / k_{0}^{s i, 2}$ in Fig. 4 were obtained from the following Eq. 10.

$$
\begin{aligned}
& \log \frac{k_{0}^{s i, 4}}{k_{0}^{s i, 2}} \\
& =\left(1-m k_{0}^{(r, 3)}\right) e_{s i}^{r_{s i},}[\operatorname{mass} \% \mathrm{Cr}]^{l .} \\
& +\left(1-m^{\prime} k_{0}^{(\cdot 3)}\right) e_{S, i}^{(\cdot, l}[\text { mass } \% C]^{\prime}
\end{aligned}
$$

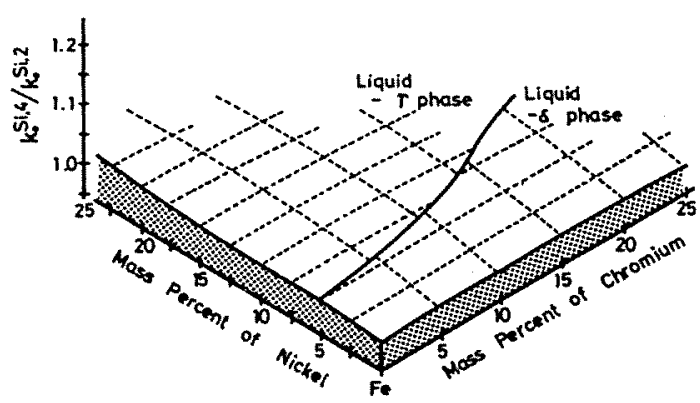

Fig. 3 Change in $k_{0}^{.5 i, 4} / k_{0}^{S i, 2}$ with the concentration of $\mathrm{Cr}$ and $\mathrm{Ni}$ in $\mathrm{Fe}-\mathrm{Cr}-\mathrm{Ni}$ base alioys

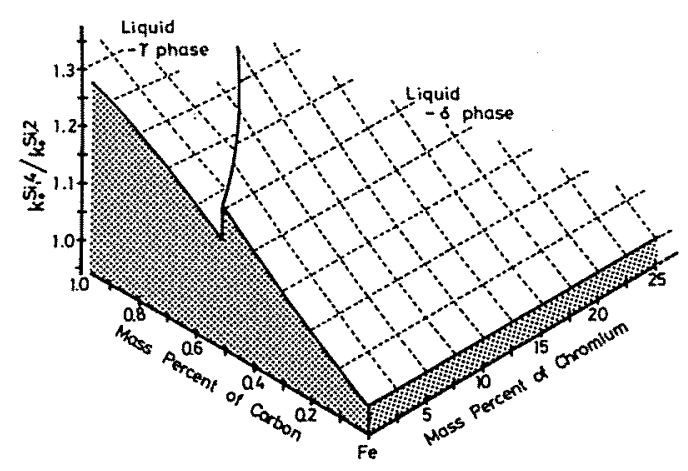

Fig. 4 Change in $k_{0}^{S i, 4} / k_{0}^{S i, 2}$ with the concentration of $\mathrm{Cr}$ and $\mathrm{C}$ in $\mathrm{Fe}-\mathrm{Cr}-\mathrm{C}$ base alloys

where $e_{S i}^{(r, t)}$ and $e_{S i}^{c, t}$ are quoted from Ref./12/, and the values of $k_{0}^{r^{\prime} r, 3}$ and $k_{0}^{C^{\prime}, 3}$ in $\mathrm{Fe}-\mathrm{Cr}-\mathrm{C}$ ternary alloys calculated by Kundrat et al. /15/ were used in Eq. 10.

As can be seen from Fig. 3, the change in $k_{0}^{s i}$ with the concentrations of $\mathrm{Cr}$ and $\mathrm{Ni}$ in $\mathrm{Fe}-\mathrm{Cr}-\mathrm{Ni}$ base alloys is very small. This corresponds to the above experimental results in Fig. 2. On the other hand, the dependence of $k_{0}^{S i}$ on the concentration of carbon in $\mathrm{Fe}-\mathrm{Cr}-\mathrm{C}$ base alloys is large as shown in Fig. 4. Thus, Figs. 3 and 4, obtained from Eqs. 9 and 10, show the influence of alloying elements on $k_{0}^{x}$ in iron alloys clearly. In other words, DIP and DIC are useful for the evaluation of the effects of solute-interactions on $k_{0}^{\prime} \dot{\text { in }}$ multi-component iron alloys.

\subsection{Fe-Hydrogen-X and Fe-Nitrogen-X Alloys}

It is important to know the equilibrium distribution behaviours of gaseous elements in relation to various phenomena during solidification of steels, but only a little information has been obtained so far concerning this subject. Therefore, the purpose of this section is to discuss the effects of various alloying elements on the equilibrium distributions of nitrogen and hydrogen between solid and liquid phases in iron base ternary system by using the foregoing $D I C$.

The variation of $D I C, \quad k_{0}^{\prime, 3} / k_{0}^{1,2}$, of nitrogen and hydrogen with the concentration of various alloying elements in $F e-i-X$ ternary systems (i: $N$ or $H$ ) is given by Eq.(II) where $m$ is assumed to be unity. 


$$
\ln \frac{k_{0}^{i, 3}}{k_{0}^{j .2}}=\left(1-k_{0}^{X .2}\right) \varepsilon_{i}^{X, L} N_{X}^{l}
$$

Since the solubility of nitrogen and hydrogen in solid and liquid alloys is considerably small, the effects of these gaseous elements on the distribution of the alloying element $X$ between solid and liquid phases can be neglected. Consequently, the value of $k_{0}^{x, 2}$ in $\mathrm{Fe}-X$ binary system was used in Eq. 11 in this work. In addition, the data of Sigworth and Elliott $/ 16 /$, Ishii et al. $/ 17,18 /$ and Morita et al. $/ 19 /$ were used for $\varepsilon_{i}^{X, t}$.

Figs. 5 and 6 show the variation of the coefficient DIC of nitrogen and hydrogen with the concentration of various alloying elements in $\mathrm{Fe}-\mathrm{N}$ and $\mathrm{Fe}-\mathrm{H}$ base ternary systems, respectively. In these figures, solid lines are the calculated results when $\delta$ phase is assumed to crystallize out of liquid solution and the values of $k_{0}^{x, 2}$ for $\delta$ phase are used in Eq. 11. Similarly, chain lines show the calculated results when the primary crystal are presumed to be $\gamma$ phase.

It is obvious from these figures that $C, S i$ etc. indicating the repulsive effects against $N$ and $H$ increase $D I C$ and on the other hand $C r, T i$ etc. showing the attractive effects against $N$ and $H$ decrease $D I C$ of these gaseous elements. The equilibrium distribution coefficients $k_{0}^{i .3}$ of nitrogen and hydrogen are calculated

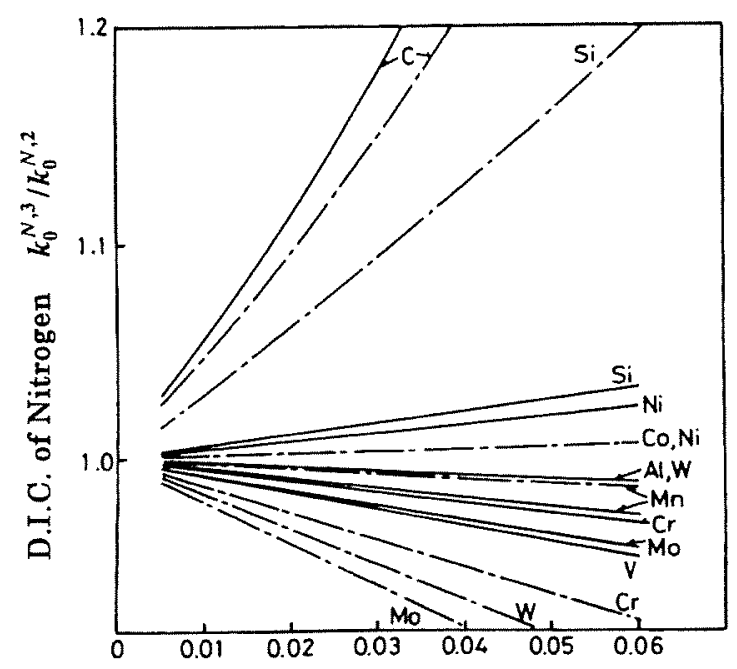

Mole Fraction of Alloying

Fig. 5 Change in DIC of nitrogen with the concentration of alloying elements in Fe alloys

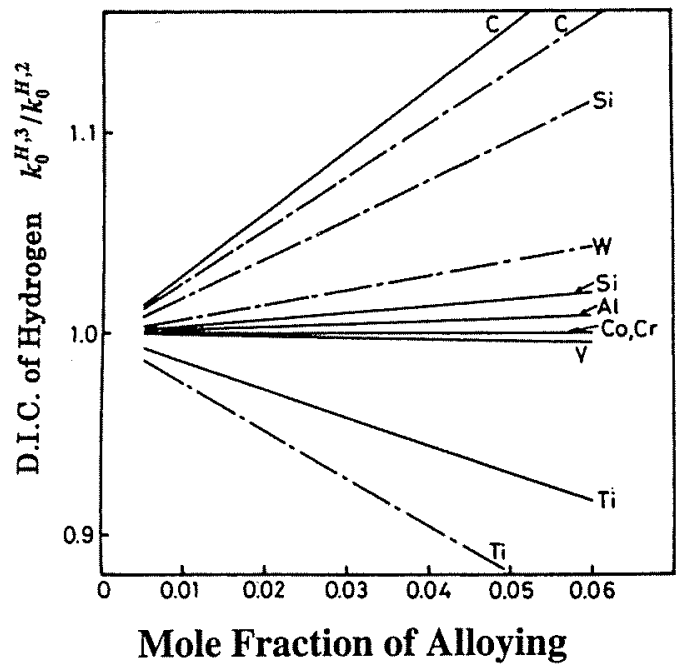

Fig. 6 Change in DIC of hydrogen with the concentration of alloying elements in Fe alloys

from the above coefficient $D I C$ and the values of $k_{0}^{i, 2}$ in $\mathrm{Fe}-\mathrm{N}$ and $\mathrm{Fe}-\mathrm{H}$ binary systems, which are evaluated from the solubility curves of these elements in pure iron.

\subsection{Fe-Phosphorus-X and Fe-Sulfur-X Alloys}

Although the concentrations of $P$ and $S$ are dilute in steels generally, these elements are known to play an important role in relation to the micro-segregation. Therefore, many studies have been carried out in order to make clear the mechanisms of their segregations and to improve them. The influences of various alloying elements, however, on the equilibrium distributions of $P$ and $S$ are not known well yet. In this section, these effects are discussed by using the foregoing coefficient $D I C$ when the concentrations of $P$ and $S$ are dilute in $F e-j-X(\mathrm{j}: P$ or $S)$ ternary systems. The change in $D I C$ of $P$ and $\mathrm{S}$ with the concentration of the alloying elements in $F e-j-X$ ternary system is given by Eq. 12 when $m=1$ is assumed.

$$
\ln \frac{k_{0}^{j, 3}}{k_{0}^{j .2}}=\left(1-k_{0}^{X .2}\right) \varepsilon_{i}^{X, l .} N_{x}^{l}
$$

Since the concentrations of $P$ and $S$ are considered to be dilute in this work, the equilibrium distribution coefficient of the alloying element in iron base binary system can be used in Eq. 12, as described in the last 
section. Furthermore, the data of Sigworth and Elliott $/ 16 /$ and Ban-ya et al. $/ 20 /$ were adopted as $\varepsilon_{j}^{X, L}$. The changes of the coefficients DIC of $P$ and $S$ with various alloying elements are shown in Figs. 7 and 8 in $\mathrm{Fe}-\mathrm{P}$ and $\mathrm{Fe}-\mathrm{S}$ base ternary alloys, respectively.

In these figures, solid lines are the calculated results when $\delta$ phase is assumed to crystallize out of liquid solution and the values of $k_{0}^{X, 2}$ for $\delta$ phase are used in Eq. 12. Similarly, chain lines show the calculated results when the primary crystal are presumed to be $\gamma$ phase. As

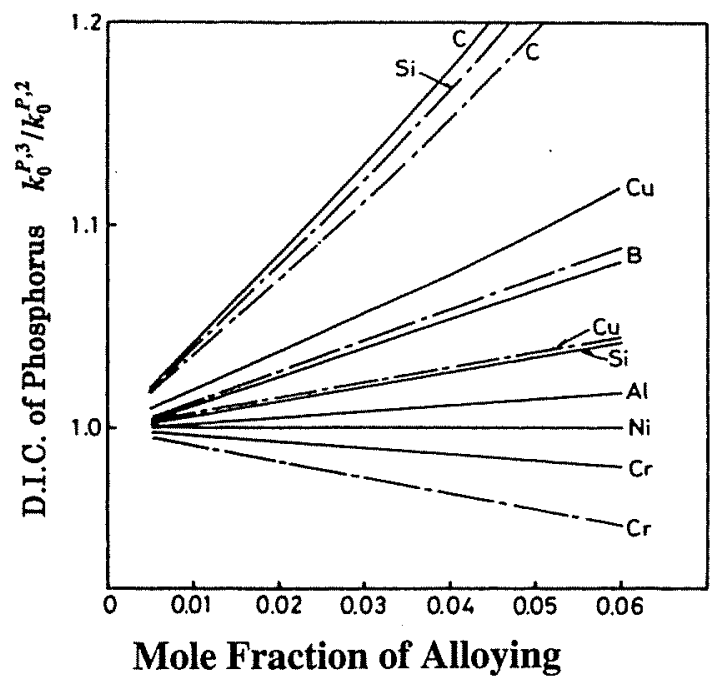

Fig. 7 Change in DIC of phosphorus with the concentration of alloying elements in Fe alloys

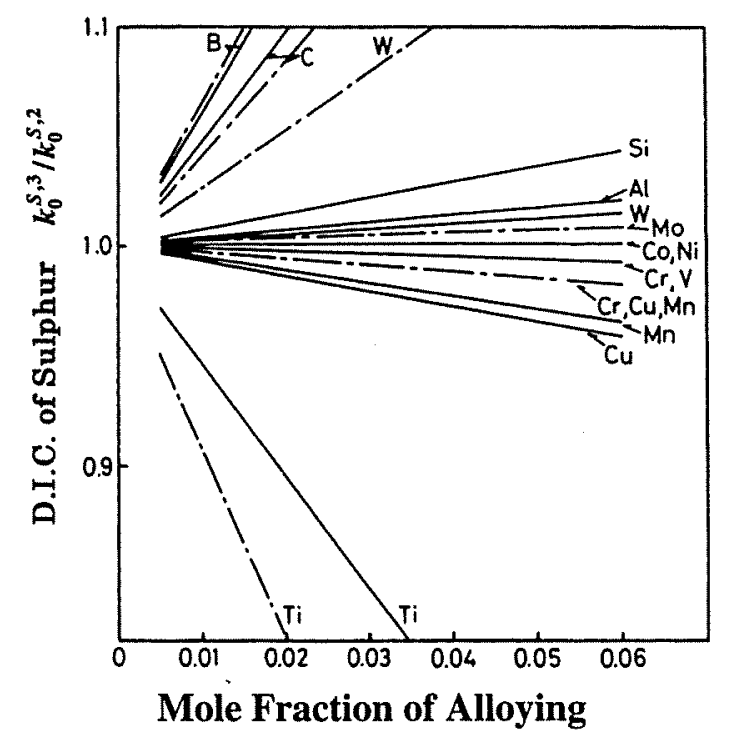

Fig. 8 Change in DIC of sulphur with the concentration of alloying elements in Fe alloys can be seen from these figures, the elements denoting the repulsive effects against $\mathrm{P}$ and $\mathrm{S}$ e.g., $C, S i$ etc. increase $D I C$ of $P$ and $S$, while the elements indicating the attractive effects against $P$ and $S$ e.g., $C r, V$ etc. decrease those of $P$ and $S$.

Thus, it is obvious that the effects of soluteinteractions on the equilibrium distributions of $N, H, P$ and $S$, which are concerned with the micro-segregation of steels, can be discussed by using the coefficient DIC.

\section{CONCLUDING REMARKS}

The equilibrium distributions of solute elements between solid and liquid phases in multi-component iron alloys were discussed thermodynamically in this work. The following new parameters:

\section{- DIC (Distribution Interaction Coefficient) $k_{0}^{X, M} / k_{0}^{X, 2}$}

\section{- DIP (Distribution Interaction Parameter) $\delta_{X}^{\gamma}=\left\{1-m k_{0}^{Y \cdot(M-1)}\right\} \varepsilon_{X}^{Y, /}$}

have been introduced to present the effects of soluteinteractions on $k_{0}^{*}$ in multi-component alloys. The effect of carbon on $k_{0}^{x}$ of several elements in $\mathrm{Fe}-\mathrm{C}$ base alloys was easily evaluated by means of $D I C$ and $D I P$.

Therefore, the small dependence of $k_{0}^{X}$ of $S i$ on the concentrations of $\mathrm{Cr}$ and $\mathrm{Ni}$ in $\mathrm{Fe}-\mathrm{Cr}-\mathrm{Ni}$ base steels was explained by the application of those parameters. In addition, the effect of the solute-interaction of $k_{0}^{x}$ of nitrogen, hydrogen, phosphorus and sulphur in iron alloys was estimated from those parameters. Thus, DIP and $D I C$ are useful for the evaluation of the effects of solute-interactions on $k_{0}^{X}$ in multi-component iron alloys.

\section{REFERENCES}

1. Z. Morita and T. Tanaka, Trans. Iron Steel Inst. Jpn., 23, 824-833 (1983).

2. Z. Morita and T. Tanaka, Trans. Iron Steel Inst. Jpn., 24, 206-211 (1984). 
3. Z. Morita, T. Tanaka, N. Imai, A. Kiyose and Y. Katayama, Trans. Iron Steel Inst. Jpn., 28, 198205 (1988).

4. N. Imai, T. Tanaka, T. Yuki, T. lida and Z. Morita, Tetsu-to-Hagane, 77, 224-230 (1991).

5. T. Umeda, Y. Kimura, M. Suzuki and T. Ogata, Proceedings of the 4th Japan-Germany Seminar on Basic Principles of Solidification of Steel with Special Regard to Continuous Casting, ISIJ, Tokyo, 106 (1980).

6. A. Kagawa, S. Moriyama and T. Okamoto, $J$. Mater. Sci., 17, 135-144 (1982).

7. A. Kagawa and T. Okamoto, Met. Sci., 14, 519524 (1980).

8. A. Kagawa, K. Iwata, A.A. Nofal and T. Okamoto, Mater. Sci. Technol., 1, 678-683 (1985).

9. A.J.W. Ogilvy, A. Ostrouskii and D.H. Kirkwood, Met. Sci., 15, 168-174 (1981).

10. J. Chipman, Basic Open Hearth Steelmaking, ed. by Physical Chemistry of Steel-making Comm. AIME, New York, 644 (1985).

11. Y. Ueshima, N. Komatsu, S. Mizoguchi and $\mathrm{H}$ Kajioka, Tetsu-to-Hagane, 73, 1551-1558 (1987).
12. H. Sako (Ed.), "Steelmaking Data Source Book", The 19th Comm. The Japan Soc. For the Promotion of Science, Gordon and Breach, New York (1988).

13. A. Yamada, T. Umeda, M. Suzuki, G. Aragane, H. Kihara and Y. Kimura, Tetsu-to-Hagane, 73, 16761683 (1987).

14. A. Yamada, T. Umeda and Y. Kimura, 10th Japan-USSR Joint Symposium on Physical Chemistry of Metallurgical Process, ISIJ, Tokyo, No.16 (1985)

15. M. Kundrat, M. Chochol and J.F. Elliott, Metall. Trans., 15B, 663-676 (1984).

16. G.K. Sigworth and J.F. Elliott, Metal Sci., 8, 98 (1974).

17. F. Ishii, S. Ban-ya and T. Fuwa, Tetsu-to-Hagane, 68, 1551-1559 (1982).

18. F. Ishii and T. Fuwa, Tetsu-to-Hagane, 68, 15601568 (1982).

19. Z. Morita, T. Tanaka and T. Yanai, Metall.Trans. B., 18B, 195-202 (1987).

20. S. Ban-ya, N. Maruyama and S. Fujino, Tetsu-toHagane, 69, 921-928 (1983). 